University of Nebraska - Lincoln

DigitalCommons@University of Nebraska - Lincoln

USDA National Wildlife Research Center - Staff Publications
U.S. Department of Agriculture: Animal and Plant Health Inspection Service

2012

\title{
A Novel Isoflurane Anesthesia Induction System for Raccoons
}

\author{
Kevin T. Bentler \\ National Wildlife Research Center, kevin.t.bentler@aphis.usda.gov \\ Daniel N. Gossett \\ National Wildlife Research Center, daniel.n.gossett@aphis.usda.gov \\ J. Jeffrey Root \\ USDA/APHIS/WS National Wildlife Research Center, jeff.root@aphis.usda.gov
}

Follow this and additional works at: https://digitalcommons.unl.edu/icwdm_usdanwrc

Bentler, Kevin T.; Gossett, Daniel N.; and Root, J. Jeffrey, "A Novel Isoflurane Anesthesia Induction System for Raccoons" (2012). USDA National Wildlife Research Center - Staff Publications. 1098.

https://digitalcommons.unl.edu/icwdm_usdanwrc/1098

This Article is brought to you for free and open access by the U.S. Department of Agriculture: Animal and Plant Health Inspection Service at DigitalCommons@University of Nebraska - Lincoln. It has been accepted for inclusion in USDA National Wildlife Research Center - Staff Publications by an authorized administrator of DigitalCommons@University of Nebraska - Lincoln. 


\title{
A Novel Isoflurane Anesthesia Induction System for Raccoons
}

\author{
KEVIN T. BENTLER, ${ }^{1}$ United States Department of Agriculture, Wildlife Services, National Wildlife Research Center, 4101 Laporte Avenue, \\ Fort Collins, CO 80521, USA \\ DANIEL N. GOSSETT, United States Department of Agriculture, Wildlife Services, National Wildlife Research Center, 4101 Laporte Avenue, \\ Fort Collins, CO 80521, USA \\ J. JEFFREY ROOT, United States Department of Agriculture, Wildlife Services, National Wildlife Research Center, 4101 Laporte Avenue, \\ Fort Collins, CO 80521, USA
}

\begin{abstract}
We developed a novel small-volume (24-L) conical-shaped isoflurane anesthesia induction chamber for use in a den chamber and tested it along with 3 conventional stand-alone induction chambers (2 clear acrylic plastic chambers and a cylindrical-shaped chamber) to determine utility for daily short-duration manipulations of captive raccoons (Procyon lotor). Although the conventional chambers were valuable, the majority of inductions were performed using the cone chamber in a pen setting. With the novel device, we were able to minimize the need for pre-anesthetic handling of animals and eliminate the need for injectable anesthesia agents. As a result, side effects normally associated with injectable agents were avoided. Mean anesthesia induction time using the cone chamber was $3.4 \mathrm{~min}(\mathrm{SD}=0.90)$. When used as designed, conventional chambers worked well, with induction times ranging from $2.7 \mathrm{~min}$ to $5.4 \mathrm{~min}$. Because the stand-alone chambers were not reliant upon den chambers for use, they may provide greater utility for field work. The conical-shaped induction chamber, however, provides an option for safe short-duration anesthetization of captive raccoons and could perhaps be used with other species and in other research settings. Published 2012. This article is a U.S. Government work and is in the public domain in the USA.
\end{abstract}

KEY WORDS anesthesia, chamber, cone, gas, immobilization, induction, inhalation, isoflurane, mesopredator, raccoon.

Wildlife disease research often necessitates daily animal manipulations that require the use of immobilizing agents. Ideally, complete immobilization diminishes the locomotor and sensory capabilities of an animal, rendering it unconscious and without pain perception (Osofsky and Hirsch 2000). Consequently, chemical immobilization provides an important tool for safe and humane handling of wildlife species. Injectable and inhalation anesthesia options are available for this purpose (Seal and Kreeger 1987, Mathews et al. 2002).

The commonly used injectable dissociative anesthetics ketamine $\mathrm{HCl}$ (usually administered with the sedative xylazine $\mathrm{HCl}$ ) and Telazol (a mixture of tiletamine $\mathrm{HCl}$ and the tranquilizer zolazepam) provide desired general anesthesia and peripheral analgesia and are considered safe, but can produce undesirable side effects (e.g., poor muscle relaxation [if used without tranquilizer or sedative], convulsions, copious salivation, increased heart rate, burning sensation at injection site, intact palpebral and corneal reflexes, open eyelids, hyper responsiveness, and ataxia during recovery) that can require special attention (Muir et al. 1989, Kreeger 2007). Additionally, injectable anesthetics may require extra use of manual restraint devices prior to and during administration or the use of remote drug-delivery systems

Received: 29 February 2012; Accepted: 25 May 2012

Published: 7 September 2012

${ }^{1}$ E-mail: kevin.t.bentler@aphis.usda.gov (i.e., blowguns, dart guns, or syringe poles; West et al. 2007). Successful yet limited use of inhalation anesthetics in wildlife (Seal and Kreeger 1987, Taulman and Williamson 1993, Lariviere and Messier 1996, Kocer and Powell 2009) suggests an alternative to injectable anesthetics in some settings.

Because inhalation anesthetics follow the dose-response concept (Sedgwick 1986), they provide good control over the depth and duration of anesthesia making them more predictable than injectable agents. With the inhaled anesthetic isoflurane, the depth of anesthesia can be changed rapidly to provide fast and smooth induction and emergence from general anesthesia (Kreeger 2007). Other advantageous characteristics of isoflurane include low toxicity (Belant 1995), relative sparing effect on cardiovascular function, and cerebral blood-flow autoregulation, as well as negligible effect on metabolism (Ludders 1992). In addition, because isoflurane does not require mixing or the use of needles, the potential for harmful human contact with an immobilizing agent is greatly reduced (Kocer and Powell 2009).

Despite its advantages, and previous use in some wildlife species (Gaynor et al. 1997, Heath et al. 1997, Breck and Gaynor 2003, Desmarchelier et al. 2007, Parker et al. 2008), the reported use of isoflurane with mesopredators is rare. Limited use of isoflurane as a successful raccoon (Procyon lotor) anesthetic has been documented (Kocer and Powell 2009, McCain et al. 2010); however, we know of no studies in which isoflurane has been used to anesthetize individual 
captive raccoons on a day-to-day basis for short-duration procedures. In our study, we tested a novel anesthesia induction chamber using isoflurane. Induction times were measured and anesthesia quality was evaluated. We also examined 3 conventional anesthesia induction chambers on a limited basis. The practicality of using isoflurane in these 4 chambers for daily short-duration anesthesia was examined with regard to safety, restraint functionality, and overall effectiveness.

\section{STUDY AREA}

We conducted this research with raccoons during an experimental infection study at the National Wildlife Research Center in Fort Collins, CO, USA. Raccoons were captivebred at the National Wildlife Research Center and were all 1 year of age. Interactions with humans prior to the studies consisted of daily pen cleaning; provisioning raccoons with food, water, and enrichment items; and periodic blood draws and veterinary examinations. The study took place in an $11.6-\mathrm{m} \times 9.8-\mathrm{m}$ simulated natural environment room with a 6.1-m-high ceiling that contained artificial lighting programmed to simulate a simple 12-hr light-dark diurnal cycle. All experiments were approved by the Institutional Animal Care and Use Committee of the National Wildlife Research Center, Fort Collins (approval no. 1810).

Raccoons were individually housed within the simulated natural environment in large caged pens $(2.4 \mathrm{~m}$ long $\times$ $1.2 \mathrm{~m}$ wide $\times 1.8 \mathrm{~m}$ high) and were provided with fresh food and water daily, enrichment toys, and litter pans that were cleaned daily. In addition to animals housed in this manner, a single raccoon was housed in a large, similarly equipped, outdoor pen. Attached to one side of each pen was a cylindrical den chamber $(50 \mathrm{~cm}$ diam $\times 61 \mathrm{~cm}$ high $)$ with a $50-\mathrm{cm}$ human-accessible top hatch and a round $25-\mathrm{cm}$ side opening continuous with the pen. Each den chamber had a volume of $120 \mathrm{~L}$.

\section{MATERIALS AND METHODS}

We constructed a novel cone-shaped anesthesia induction chamber $(36 \mathrm{~cm}$ high $\times 50 \mathrm{~cm}$ diam) with an open base, assembled from an engineered seamless high-density polyethylene plastic cone, to be inserted into a raccoon den

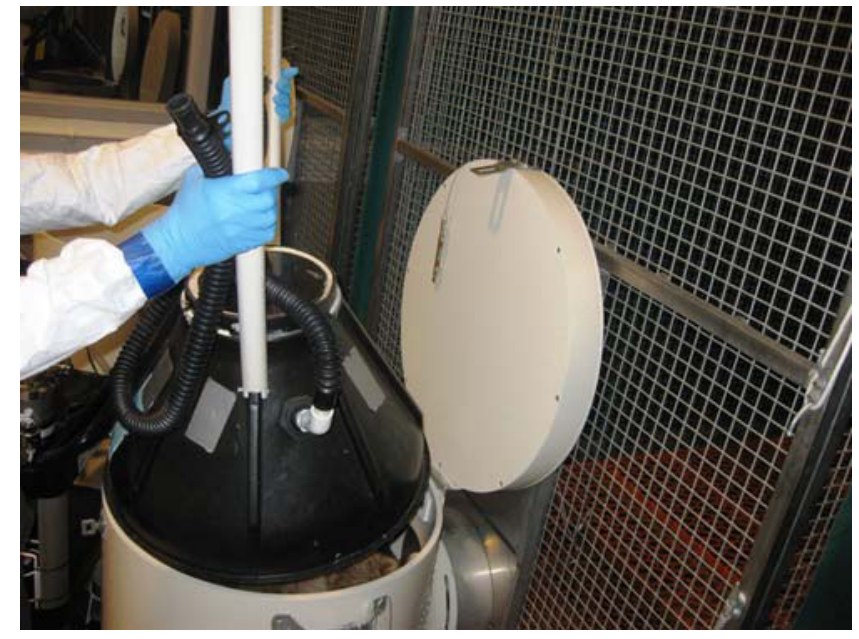

Figure 1. Cone-shaped anesthesia induction chamber measuring $36 \mathrm{~cm}$ high $\times 50 \mathrm{~cm}$ in diameter, with hinged manipulation handles, clear polycarbonate view port, and $22-\mathrm{mm}$ vapor ports being inserted into a raccoon den chamber via a momentarily opened top hatch. The cone is designed to restrain an animal within the den chamber.

chamber via a momentarily opened top hatch (Table 1 ). The cone itself was designed to restrain an animal within the den chamber described above (Fig. 1). Furthermore, the cone base was formed so as to produce an adequate vapor seal against a den chamber floor. Integrated with a den chamber, the cone chamber $(24 \mathrm{~L})$ effectively reduced the larger den chamber volume by $80 \%$, potentially making the system an ideal anesthesia induction chamber. We constructed the cone chamber with 2 hinged manipulation handles fabricated from polyvinyl chloride pipe, a clear polycarbonate plastic view port, and extended 22-mm vapor inlet and outlet ports (Figs. 1 and 2). The cone was designed to 1) separate animal from researcher, 2) confine the animal, and 3) anesthetize the animal.

We also constructed 2 box-type chambers and a cylinder chamber (Table 1) for limited use during these studies. We designed Box 1 (Fig. 3) to hold a live-catch trap $(81 \mathrm{~cm} \times 25 \mathrm{~cm} \times 30 \mathrm{~cm}$; Tomahawk Live Trap Co, Hazelhurst, WI) containing a raccoon. A separate sealed lid was used to contain anesthesia vapors. We designed

Table 1. Attributes and results for custom anesthesia chambers used for captive raccoon anesthesia with isoflurane.

\begin{tabular}{|c|c|c|c|c|c|c|c|}
\hline $\begin{array}{l}\text { Chamber } \\
\text { type }\end{array}$ & Construction & $\begin{array}{c}\text { Interior } \\
\text { dimensions } \\
(\mathrm{cm})\end{array}$ & $\begin{array}{c}\text { Vapor } \\
\text { vol } \\
(\mathrm{L})\end{array}$ & $\begin{array}{l}\text { Wt } \\
(\mathbf{k g})\end{array}$ & $\begin{array}{c}\text { No. of } \\
\text { times } \\
\text { used }\end{array}$ & $\begin{array}{c}\text { Mean } \\
\text { induction } \\
\text { time (min) }\end{array}$ & SD \\
\hline Cone & $\begin{array}{l}\text { Engineered seamless high-density polyethylene plastic cone with } \\
\text { clear polycarbonate view port, handles }\end{array}$ & $50 \times 36^{\mathrm{a}}$ & $24^{\mathrm{b}}$ & 2.1 & 102 & 3.4 & 0.90 \\
\hline Box 1 & $\begin{array}{l}\text { Clear acrylic plastic with glued seams, aluminum corner } \\
\text { reinforcements, and lid with rubber seal }\end{array}$ & $83 \times 28 \times 33^{c}$ & 78 & 8.7 & 7 & 5.4 & 0.95 \\
\hline Box 2 & $\begin{array}{l}\text { Clear acrylic plastic with glued seams, aluminum-reinforced base, } \\
\text { and sliding door }\end{array}$ & $36 \times 29 \times 33$ & 34 & 4.6 & 10 & 2.9 & 1.3 \\
\hline Cylinder & $\begin{array}{l}\text { Modified plastic bucket with clear polycarbonate view port } \\
\text { and separate plunger }\end{array}$ & $28 \times 28$ & $17^{\mathrm{d}}$ & 3.3 & 2 & 2.8 & 0.09 \\
\hline
\end{tabular}

${ }^{a}$ Cone and cylinder type chamber dimensions given as base diam $\times$ height.

${ }^{\mathrm{b}}$ Chamber volume with cone fully inserted into den chamber.

${ }^{\mathrm{c}}$ Box-type chamber dimensions given as length $\times$ width $\times$ height.

${ }^{\mathrm{d}}$ Cylinder chamber volume with plunger fully seated. 


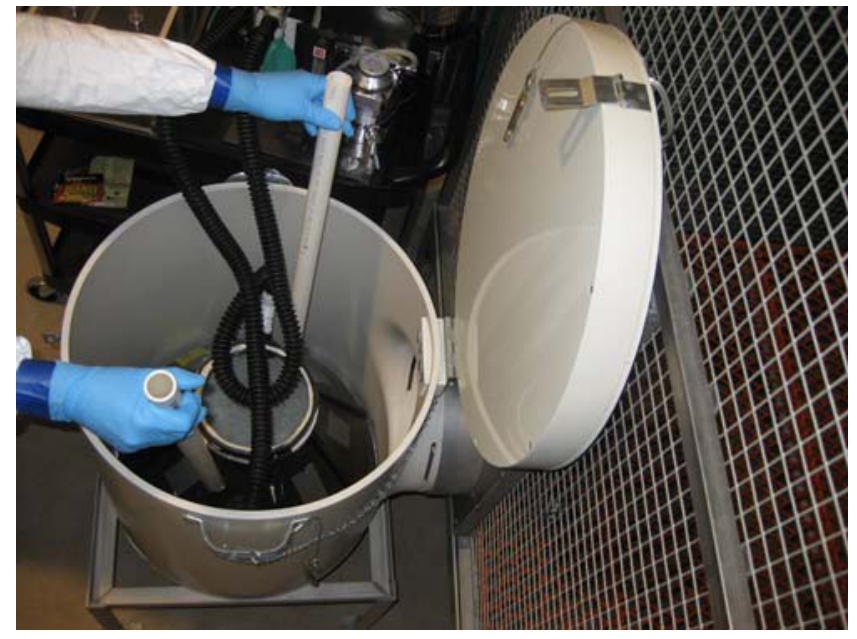

Figure 2. Den chamber with cone induction chamber fully inserted creating a final volume of $24 \mathrm{~L}$. Isoflurane vapor is delivered via hoses attached to an anesthesia machine.

Box 2 (Fig. 4) to be a transfer chamber capable of accepting an animal from a den chamber or live-catch trap. A separate sliding door inserted into the front of the chamber was used to contain anesthesia vapor and for raccoon restraint. Clear acrylic plastic construction allowed unobstructed views into both box-type chambers. We constructed the cylinder chamber (Fig. 5) from a plastic bucket (i.e., a nominal 6-gallon bucket), which was conceptually similar to Box 2 (i.e., also designed as a transfer chamber). A separate clear plastic sliding door inserted into the front of the chamber was designed to retain an animal inside during transfer and holding, but not specifically for containing anesthesia vapor. Instead, we constructed a clear plastic plunger with a plastic seal to be inserted into the chamber for this purpose. A clear plastic view panel was integrated into the end of the chamber for animal monitoring. We designed each induction chamber with an extended 22-mm-diameter vapor inlet and outlet ports for the attachment of anesthesia hoses.

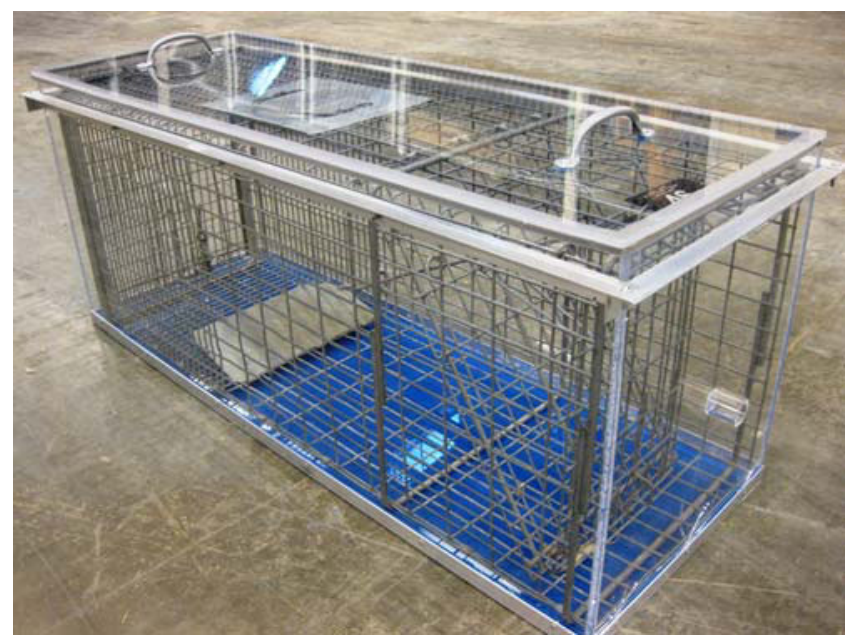

Figure 3. Box 1 anesthesia induction chamber with $81 \mathrm{~cm} \times 25 \mathrm{~cm} \times$ $30 \mathrm{~cm}$ live-catch trap and lid in place. A vapor port is visible on the right.

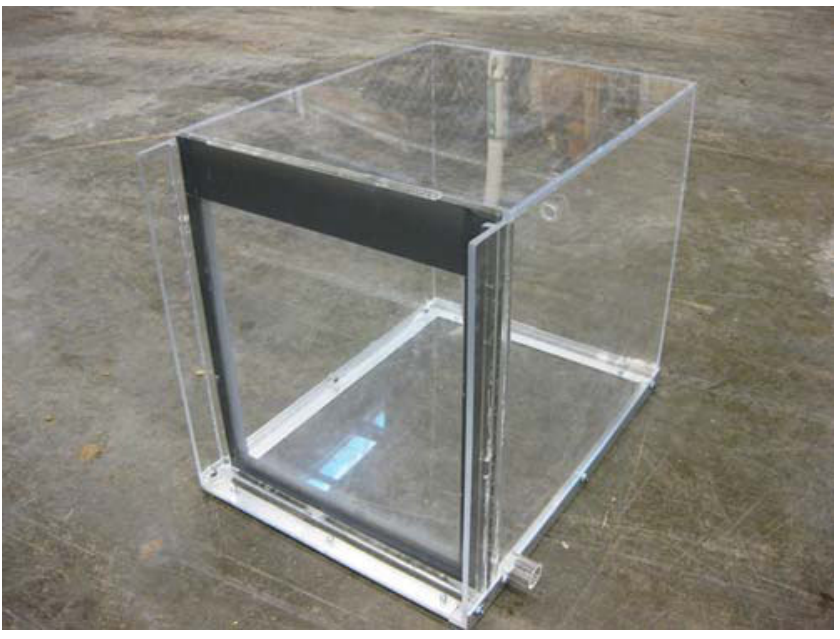

Figure 4. Box 2 anesthesia induction chamber (transfer chamber) with sliding door in place. Vapor ports are visible protruding from the side and on the rear of the chamber.

We carried out immobilization procedures once daily for 14 days, over a course of 2 study periods, for the purpose of obtaining biological samples (i.e., oral, nasal, and rectal swabs) and evaluating the induction chambers. Signs of stress (e.g., scratching and biting the anesthesia chamber, hyperactivity, aggression, and fear), animal behavior (i.e., temperament toward daily handling and induction-chamber exposure), and anesthesia quality (i.e., the level of agitation during induction, the adequacy of anesthesia depth, as needed to safely perform necessary procedures without discomfort, and the swiftness of the recovery) were monitored and noted when remarkable. We carried out anesthesia procedures in the morning. To reduce the chance of vomiting and possible airway aspiration of gastric fluids, raccoons were not fed until all sampling was completed. Induction times and type of induction chamber were recorded.

With all chambers, we induced anesthesia with an initial $5 \%$ concentration of isoflurane delivered at a rate of $4 \mathrm{~L} / \mathrm{min}$

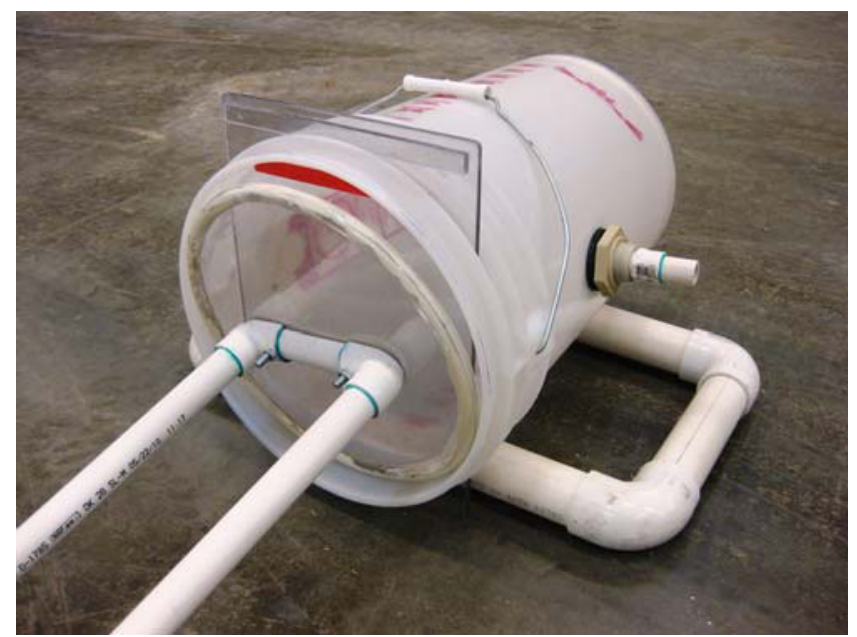

Figure 5. Cylinder anesthesia induction chamber with sliding door in place and plunger ready. Anesthesia hose attaches to the side-mounted vapor port shown. 
using a Matrx calibrated precision-vaporizer anesthesia machine (Midmark Corp., Versailles, OH) with 100\% oxygen as the carrier gas. We used induction-chamber viewing panels to monitor the animal before and during anesthetic induction. Sampling procedures could be performed quickly; therefore, only a light plane of anesthesia was desired and necessary. A raccoon was reliably assessed to be safe to handle and sufficiently anesthetized, for the purpose of obtaining quick swab samples, when it became recumbent and its righting response, sensitivity to tactile stimulation, and muscle tone were appreciably reduced or absent. We reduced reactions to external stimuli by keeping animals in their den chambers, or by otherwise limiting light exposure (i.e., by covering induction chambers and eyes of animals or repositioning animals) and minimizing unnecessary physical contact during all phases of anesthesia and sampling.

Once an animal was safe to handle, we reduced the oxygenvapor flow rate and we obtained study-related samples. If necessary after the initial induction, we delivered additional anesthesia under careful observation at a flow rate of 1$2 \mathrm{~L} / \mathrm{min}$ via an anesthesia face mask. After sampling, we removed the anesthetic, allowed animals to recover, and noted time to recovery. We defined recovery time as the time it took for an animal to regain a firm sitting or standing position. Because sampling procedures could be performed rapidly, were minimally invasive, and did not cause perceptible pain, we often found that the use of anesthetic beyond the induction phase was unnecessary.

\section{RESULTS}

We recorded data during 121 anesthesia procedures performed on 19 raccoons (Table 1). Ten raccoons were anesthetized once daily for 7 days during the first study period and 9 more raccoons were anesthetized in the same manner during a second 7-day period. A typical sampling session took $2 \mathrm{hr} /$ day to complete. In general, all phases of anesthesia were uneventful, characterized by smooth inductions and greatly diminished locomotor and sensory capabilities allowing for safe sampling without discomfort. On only 5 occasions (5 animals) did we note excessive agitation (i.e., uncharacteristic scratching and biting on the chamber). During anesthetic induction, we observed 2 raccoons position their heads near the top of the cone chamber. The induction times for these animals were $5.5 \mathrm{~min}$ and $6.6 \mathrm{~min}$. We observed no adverse effects, such as muscle tension, spasms, seizures, excessive salivation, vomiting, airway aspiration, respiratory difficulties, or cardiovascular complications.

We noted no behavioral changes in regard to animal disposition toward anesthesia or den chambers over time. Raccoons inclined toward being in their den chambers tended to stay inside and could be processed using the cone chamber with relative ease. Animals less inclined to be in their den chambers tended to maintain their aversion for the duration of the studies and were more difficult to process. When necessary, a restraint device was employed to manipulate a raccoon into an anesthesia or den chamber. At all times, stress levels were monitored via behavioral cues (as previously described) and used to guide manipulation efforts.

Box 1, designed to hold a live-catch trap, was used on 7 occasions on 3 different raccoons, while Box 2 was used 10 times on 3 raccoons (Table 1). The cylinder chamber was only used 2 times to anesthetize 2 animals and induction times were $2.8 \mathrm{~min}$ and $2.7 \mathrm{~min}$. Use of these 3 chambers was generally restricted to specific circumstances that precluded the use of the cone chamber (i.e., animal was not in den chamber, cone chamber was not available, and/or use of the cone chamber would have resulted in unwarranted stress). The single animal housed outside was anesthetized solely using Box 2 , because the cone chamber was unavailable at that location. Another raccoon was anesthetized daily using Box 1 (5 times), Box 2 (1 time), and the cylinder chamber (1 time). Mean induction times required for immobilization are shown in Table 1.

As designed, the cone induction chamber functioned as a confinement vessel and anesthesia chamber, as well as a barrier between animals and researchers. The majority of raccoons were anesthetized in the cone-chamber system (Table 1). We recorded data 102 times for varying degrees of cone induction-chamber use (i.e., using the cone, 2 raccoons were anesthetized 4 times, 3 raccoons were anesthetized 5 times, 5 raccoons were anesthetized 6 times, and a final 7 were anesthetized 7 times). Two raccoons would not go into their den chambers and were, therefore, never exposed to the cone chamber. The mean induction time when using the cone-type chamber was $3.4 \min (\mathrm{SD}=0.90$; Table 1$)$. Because recovery is directly related to duration of anesthesia (i.e., recovery time varies as anesthesia duration time; Steffey 1996), the short periods of anesthesia sustained by the raccoons greatly contributed to rapid recovery times. As such, recovery from cone-chamber anesthesia, as with all our induction chambers, was rapid, with raccoons sitting or standing in 1-5 min.

\section{DISCUSSION}

We utilized the cone induction chamber the most because raccoons either preferred their den chambers or could be manipulated into them with reasonable efficiency. This gave the cone induction chamber a decisive advantage over the other chambers tested in a captive pen setting. Typically, a raccoon was confined inside a den chamber; the cone chamber was inserted and connected to the anesthesia machine, and induction was initiated. It was possible to insert the cone chamber into the momentarily open den chamber quickly enough to negate any need for an additional separation device. On 2 occasions, however, it was necessary to use a restraint device to redirect raccoons back into their den chamber. Although we typically did not find an additional device to be necessary, a flat piece of wood, plastic, or metal large enough to fit over the top of the den chamber may have provided an extra level of security. Once a raccoon was confined under the cone, induction with isoflurane was typically smooth and uneventful and resulted in ideal anesthetic state for obtaining daily swab samples. Agitated states during induction (noted on only 5 occasions 
in 5 different animals) were observed to be infrequent. The lightweight cone was relatively easy to manipulate, which allowed for quick and secure restraint of raccoons in their den chambers with minimal risk to animals and researchers. The small volume could be filled with anesthetic vapor faster than the larger conventional chambers, resulting in shorter induction times and shorter procedures. The small volume also resulted in less isoflurane used, thereby reducing human and environmental exposure to anesthetic vapors when removing an animal from the chamber.

Although the cone chamber functioned well in a pen setting, our conventional induction chambers have potential utility, if not advantages for field work. This is especially the case for Box 1. Although it required a greater amount of isoflurane, it could completely accommodate a live-catch trap, eliminating the need for any direct pre-anesthetic handling of raccoons. Transfer chambers, such as Box 2 and the cylinder chamber, are lightweight and manageable and can be used to anesthetize animals transferred from a trap or other container. In addition to eliminating the need for injectable immobilizing agents, these 3 chambers also eliminate or reduce the need for further animal transferring and constraint measures. The clear plastic viewing panels, of which our conventional induction chambers were constructed, made it possible to monitor animals before, during, and after induction.

We found that the conventional chambers required more time and effort to employ in a pen setting. Large induction chambers, such as Box 1, require a greater amount of isoflurane to become saturated to a level needed to induce anesthesia and, therefore, can result in longer induction times. Also, chambers constructed of acrylic plastic, such as Box 1, were susceptible to cracking. Use of a harder plastic, such as polycarbonate, may provide a solution to this type of damage. The polycarbonate components we used in our chambers (i.e., view ports in the cylindrical and cone chambers) showed no signs of cracking.

We found the cone-type anesthesia chamber to be exceptionally well-suited for wildlife disease research and expect that other studies requiring daily sampling could benefit from this system as well. The cone chamber provided us with the best solution for short-duration immobilization of raccoons in a pen setting. In addition to allowing for short induction times and high-quality anesthesia, it also met our desired safety and restraint functionality criteria and fulfilled our need to minimize pre-anesthetic handling of animals. Despite its light weight, the seamless and flexible highdensity polyethylene cone possessed superior toughness and resilience when compared with chambers made of clear acrylic plastic with glued seams.

Though designed for use with an outer cylindrical den chamber, and not specifically tested outside of a research setting, a modified cone induction chamber may be useful in the field. The addition of a portable lightweight cylinder or tub (see Kocer and Powell 2009) may provide some utility for field applications. The short recovery times based on our definition of time to recovery (i.e., the time required for an animal to regain a firm sitting or standing position) may not be realistic in a field setting due to potential hazards in nature (i.e., vulnerability to predation or accidental injury). As a result, it would be prudent to ensure that an animal is fully alert and able to walk without stumbling before release back into the wild.

\section{FIELD IMPLICATIONS}

With regards to induction and recovery times, isoflurane anesthesia induction chambers appear to have an advantage over injectable agents for field work. Induction and emergence from vapor anesthetics, such as isoflurane, is rapid. Isoflurane recovery times observed in wild raccoons have been reported to be no $>12 \mathrm{~min}$ (Kocer and Powell 2009). Alternatively, anesthesia recovery times associated with injectable anesthetics can be prolonged (108.8 min; Deresienski and Rupprecht 1989). Conventional, box-type chambers have advantages for field work. For example, they permit animal transfer with relative ease, can accommodate entire live traps, and provide good visibility of enclosed animals. Large box-type chambers may, however, be cumbersome in the field and require extra isoflurane. Field use of smaller induction chambers may ultimately provide a lightweight, low-volume alternative.

\section{ACKNOWLEDGMENTS}

We recognize, with much gratitude, the technical assistance provided by J. Ellis (National Wildlife Research Center) and thank the Animal Care Unit staff at the National Wildlife Research Center for their assistance and logistical support. We also thank T. Fry for her assistance in obtaining raccoons for this study. In addition, Dr. G. Gathright, DVM (National Wildlife Research Center, Animal Care Unit), provided valuable advice and insight with regard to induction-chamber designs and fabrication for which we are grateful.

\section{LITERATURE CITED}

Belant, J. L. 1995. Isoflurane as an inhalation anesthetic for muskrats (Ondatra zibethicus). Journal of Wildlife Diseases 31:573-575.

Breck, S. W., and J. S. Gaynor. 2003. Comparison of isoflurane and sevoflurane for anesthesia in beaver. Journal of Wildlife Diseases 39: 387-392.

Deresienski, D. T., and C. E. Rupprecht. 1989. Yohimbine reversal of ketamine-xylazine immobilization of raccoons (Procyon lotor). Journal of Wildlife Diseases 25:169-174.

Desmarchelier, M., M. Cheveau, L. Imbeau, and S. Lair. 2007. Field use of isoflurane as an inhalant anesthetic in the American marten (Martes americana). Journal of Wildlife Diseases 43:719-725.

Gaynor, J. S., J. Wimsatt, C. Mallinckrodt, and D. Biggins. 1997. A comparison of sevoflurane and isoflurane for short-term anesthesia in polecats (Mustela eversmanni). Journal of Zoo Wildlife Medicine 28:274279.

Heath, R. B., R. DeLong, V. Jameson, D. Bradley, and T. Spraker. 1997. Isoflurane anesthesia in free ranging sea lion pups. Journal of Wildlife Diseases 33:206-210.

Kocer, C. J., and L. A. Powell. 2009. A field system for isoflurane anesthesia of multiple species of mesopredators. American Midland Naturalist 161:406-412.

Kreeger, T. J. 2007. Handbook of wildlife chemical immobilization. International Wildlife Veterinary Services, Laramie, Wyoming, USA.

Lariviere, S., and F. Messier. 1996. Field anesthesia of striped skunks, Mephitis mephitis, using halothane. Canadian Field Naturalist 110:703705 . 
Ludders, J. W. 1992. Advantages and guidelines for using isoflurane. Veterinary Clinics of North America: Small Animal Practice 22:328-331.

Mathews, F., P. Honess, and S. Wolfensohn. 2002. Use of inhalation anaesthesia for wild mammals in the field. Veterinary Record 150:785787.

McCain, S. L., M. C. Allender, M. Bohling, E. C. Ramsay, F. Morandi, and K. M. Newkirk. 2010. Thyroid neoplasia in captive raccoons (Procyon lotor). Journal of Zoo and Wildlife Medicine 41:121-127.

Muir, W. W., J. A. E. Hubbell, and R. Skarda. 1989. Handbook of veterinary anesthesia. Mosby, St. Louis, Missouri, USA.

Osofsky, S. A., and K. J. Hirsch. 2000. Chemical restraint of endangered mammals for conservation purposes: a practical primer. Oryx 34:27-33.

Parker, W. T., L. I. Muller, R. R. Gerhardt, D. P. O'Rourke, and E. C. Ramsay. 2008. Field use of isoflurane for safe squirrel and woodrat anesthesia. Journal of Wildlife Management 72:1262-1266.

Seal, U. S., and T. J. Kreeger. 1987. Chemical immobilization of furbearers. Pages 191-215 in M. J. Novak, A. Baker, M. E. Obbard, and B. Malloch, editors. Wild furbearer management and conservation in North America. Ontario Trappers Association, North Bay, Ontario, Canada.

Sedgwick, C. J. 1986. Inhalation anesthesia for captive wild mammals, birds, and reptiles. Pages 52-56 in M. E. Fowler, editor. Zoo and animal medicine. Second edition. W.B. Saunders, Philadelphia, Pennsylvania, USA.

Steffey, E. P. 1996. Inhalation anesthetics. Pages 297-329 in J. C. Thurmon, W. J. Tranquilli, and G. J. Benson, editors. Lumb and Jones' veterinary anesthesia. Third edition. Williams and Wilkins, Baltimore, Maryland, USA.

Taulman, J. F., and J. H. Williamson. 1993. A simple apparatus and technique for anesthetizing raccoons. American Midland Naturalist 129:210-214.

West, G., D. Heard, and N. Caulkett. 2007. Zoo animal and wildlife immobilization and anesthesia. Blackwell, Ames, Iowa, USA.

Associate Editor: M. Peterson. 